\title{
Expanding the reach of probiotics through social enterprises
}

\author{
G. Reid $^{1 *}$, R. Kort ${ }^{2,3,4}$, S. Alvarez ${ }^{5}$, R. Bourdet-Sicard ${ }^{6}$, V. Benoit ${ }^{7}$, M. Cunningham ${ }^{8}$, D.M. Saulnier', J.E.T. van \\ Hylckama Vlieg ${ }^{10}, \mathrm{H}$. Verstraelen ${ }^{11}$ and W. Sybesma ${ }^{2}$ \\ ${ }^{1}$ Canadian Research and Development Centre for Probiotics, Microbiology \& Immunology, and Surgery, University of Western \\ Ontario, Room F3-106, P.O. Box 5777, STN B, London, N6A 4V2 Ontario, Canada; ${ }^{2}$ Yoba for Life foundation, Hunzestraat 133- \\ A, 1079 WB Amsterdam, the Netherlands; ${ }^{3}$ TNO Microbiology and Systems Biology, P.O. Box 360, 3700 AJZeist, the Netherlands; \\ ${ }^{4}$ VU University Amsterdam; Micropia, Natura Artis Magistra, Plantage Kerklaan 38-40, 1018 CZ Amsterdam, the \\ Netherlands; ${ }^{5}$ Reference Centre for Lactobacilli (CERELA-CONICET), Chacabuco 145, Tucuman 4000, Argentina; \\ ${ }^{6}$ Danone Access, Africa \& India, Danone Nutricia Research, Avenue de la Vauve, 91767 Palaiseau, France; ${ }^{7}$ General Mills, \\ Nutrition and Technology Solutions, 9000 Plymouth Avenue N, Minneapolis, MN 55427, USA; ${ }^{8}$ Research and Development, \\ Metagenics (Aust) Pty Ltd., P.O. Box 675, Virginia BC, Queensland 4014, Australia; ${ }^{9}$ Novozymes A/S, Hillerødgade 42, 2200 \\ Frederiksberg, Denmark; ${ }^{10}$ Chr Hansen AS, Bøge Alle 10, 2970 Hoersholm, Denmark; ${ }^{11}$ Vulvovaginal Disease Clinic, Dept. \\ of Obstetrics \& Gynaecology, Ghent University Hospital 0P4, Corneel Heymanslaan 10, 9000 Gent, Belgium; gregor@uwo.ca
}

Received: 28 January 2018 / Accepted: 20 March 2018

(c) 2018 Wageningen Academic Publishers

\section{OPEN ACCESS C(1)(-) OPINION PAPER}

\begin{abstract}
The rapid rise in microbiome and probiotic science has led to estimates of product creation and sales exceeding $\$ 50$ billion within five years. However, many people do not have access to affordable products, and regulatory agencies have stifled progress. The objective of a discussion group at the 2017 meeting of the International Scientific Association for Probiotics and Prebiotics was to identify mechanisms to confer the benefits of probiotics to a larger portion of the world's population. Three initiatives, built around fermented food, were discussed with different methods of targeting populations that face enormous challenges of malnutrition, infectious disease, poverty and violent conflict. As new candidate probiotic strains emerge, and the market diversifies towards more personalised interventions, manufacturing processes will need to evolve. Information dissemination through scientific channels and social media is projected to provide consumers and healthcare providers with rapid access to clinical results, and to identify the nearest location of sites making new and affordable probiotic food and supplements. This rapid translation of science to individual well-being will not only expand the beneficiaries of probiotics, but also fuel new social enterprises and economic business models.
\end{abstract}

Keywords: probiotics, fermented food, social business, developing world

\section{Introduction}

The past fifteen years has seen a rapid rise in probiotic products being sold worldwide. There are several reasons for this, including companies with multinational sales reach, evidence generated from clinical studies that supports the consumers' need for products with health benefits, and a recognition that microbes play an enormous role in human and planetary life (Horton and Lo, 2015; Omenn, 2010; Postler and Gosh, 2017; Younes et al., 2017). Many studies have documented the positive effects of probiotics and fermented foods (Hill et al., 2014; Marco et al., 2017), further increasing the demand for the products.

However, there is deficit in the inability of products to reach arguably the neediest women, men and children in developing countries. It is in sub-Saharan Africa, including Kenya, Tanzania and Uganda, in Asian countries like Nepal and Bangladesh, and in parts of South America where poverty and malnutrition take a massive toll in terms of morbidity and average lifespan (World Atlas, 2017; World Statistics, 2014). 
The reported observations of Metchnikoff equating longevity with intake of fermented milk (Podolsky, 1998) have been part of the philosophy behind probiotics replenishment of beneficial microbes. Prospective and retrospective studies correlate intake of fermented food with lower rates of bladder cancer, cardiovascular disease and type II diabetes (Keszei et al., 2010; Sonestedt et al., 2011), non-communicable diseases that affect more and more people living in the developing world (Allen et al., 2017).

A stumbling block in making probiotics available to the poorest people on the planet, in terms of financial and dietary poverty, is the strategic choice of most probiotic companies to work with business models that do not target people living at the bottom of the pyramid. Probiotic products are sold in some developing countries as premium products, which, for the people who might need them most, are simply unaffordable. Deficient infrastructure and access to good quality milk are often issues that would require a high investment. Sending finished products under humanitarian aid, is difficult due to the need to refrigerate finished foods like yogurt, and could at best only bring temporary relief.

Africa has a rich and long history of people making traditional fermented foods. Further development of these as delivery vehicles for probiotic bacteria could contribute towards reaching the United Nations Millennium Development Goals of eradication of poverty and hunger, reduction in child mortality rates and improvement of maternal health (Franz et al. 2014; United Nations, 2015). A forum was set up at the 2017 annual meeting of the International Scientific Association for Probiotics and Prebiotics (ISAPP) to discuss and understand the success of initiatives that provide people in the most challenging environments with access to probiotic food.

\section{The Argentinian example}

The process by which Lactobacillus rhamnosus CRL1505 has become integrated into the Official Nutritional Programs of Argentina and given to more than three hundred thousand children during school days provides an inspiring lesson for all countries. This probiotic strain was isolated from goat milk in north-western Argentina by scientists at the CERELA-CONICET research institute in Tucuman and shown through a series of studies to reduce the incidence and severity of intestinal and respiratory infections in children (diarrhoea, upper airway infections, pharyngitis and tonsillitis) and significantly increase immunoglobulin A in saliva (Salva et al., 2010). The strain influenced lung immune-coagulative reaction triggered by Toll-like receptor 3 activation and its ability to modulate the production of pro-inflammatory and anti-inflammatory mediators helped it clear respiratory syncytial virus and influenza virus, and still control immune-coagulative responses and normal function in the lung despite viral attack (Zelaya et al., 2014).

A yogurt containing the CRL1505 strain was produced and tested on children attending preschool day-care community centres using a randomised, double blind, placebo controlled study. The significant decrease in the duration and severity of respiratory disease (Villena $e t$ al., 2012) attracted the attention of people working at the provincial government. They decided to cover the cost of making it available to all children in financially challenged school districts. In time, the national government decided to expand the reach around the country using different manufacturers. The term 'Probiotics for Everyone' was adopted as the slogan for the program (Villena et al., 2012).

Recognising the different taste and texture preferences of the population, the probiotic is now produced as Yogurito in yogurt, as well as different formulations, including a chocolate drink. For a country that is not ranked highly for its gross domestic product (GDP) (Countryeconomy.com, 2017), this clearly shows that it has prioritised nutrition in children.

Although the financial support by the Argentinan local governments can be seen as an example for many other countries, government priorities may change and the program could be cancelled. In that case, other means of program support need to be found or the recipients will return to being depleted of the benefits of the food. The Argentinian government hopes to generate a payback for the nation when children are healthier and attend classes more frequently, thereby improving the chances of a better future.

\section{East Africa}

A different model has been introduced to sub-Saharan countries and Nepal. The concept originated in 2004 in response to a call for assistance for people dying from HIV/AIDS. The loss of bread-winners and side effects of diarrhoea, skin rashes and fatigue from the disease and its treatment were placing enormous burden on women in the communities. A program termed Western Heads East (WHE) was established by the staff, faculty and students of The University of Western Ontario in London, Canada. Students went to Mwanza, Tanzania and taught a local women's group how to produce yogurt supplemented with probiotic L. rhamnosus GR-1 (termed Fiti) (Reid, 2010). A series of studies showed that a number of health benefits could be accrued, including reduction in fatigue, diarrhoea and skin rashes, and in some cases improvement in CD4 counts in HIV patients (Anukam et al., 2008; Irvine et al., 2010; Kort and Sybesma, 2012). Within a few years, eleven community kitchens were in operation in Mwanza providing an estimated 3,500 recipients with the probiotic yogurt. 
However, the GR-1 strain had to be propagated at a suitable site, in this case the National Institute for Medical Research, and the 'yogurt mamas' had to travel to collect it, and then complete the production of the yogurt. This was effective initially, but became too much work with increasing volumes. Eventually, the institute stopped producing the probiotic. Fortunately, a Dutch non-profit organisation, the Yoba for Life Foundation (Y4L), had discovered a way to avoid this propagation step. Started in 2011, Y4L created the L. rhamnosus Yoba 2012 strain, a clone of the world's most documented probiotic bacterium L. rhamnosus GG. They deposited the strain at the BCCM/LMG bacterial culture collection (LMG 27229) after the original patent of $L$. rhamnosus GG expired. Sequence comparison could confirm that all technical and functional properties attributed to the original strain exist with the same level of certainty in the Yoba 2012 strain as in actual commercial clones of L. rhamnosus GG, branded as LGG ${ }^{\oplus}$ (Kort and Sybesma, 2012). They then created a two-strain sachet containing Yoba 2012 plus a Streptococcus thermophilus C106 strain that was highly efficient at fermenting milk (Kort et al., 2015; Westerik et al., 2016). They showed that a 1 gram sachet could produce 100 litres of probiotic fermented milk, including the propagated L. rhamnosus Yoba strain. They placed a simple diagram on the back of the label to describe the production steps.

This innovative breakthrough led to the establishment of community kitchens around Kampala in Uganda. The sachets are affordable for the yoghurt producers at around US $\$ 0.60$ each, and once volumes of finished product reach 20 litres, the production units (PUs) are profitable. In 2015, supported by a grant from the Canadian International Food Security Research Fund, researchers from WHE and Y4L teamed up with Heifer International and Jomo Kenyatta University of Agriculture and Technology to create a Fermented Food For Life (FFFL) program and leverage the probiotic starter culture innovation in order to reach 250,000 consumers in Kenya, Tanzania and Uganda. With two months remaining of the funding over 220 PUs have been established in communities numbering in the millions of potential consumers where probiotics have never been made accessible. The locally operating PUs can be a singlerun business making 20 litres of yoghurt per batch, to larger enterprises making 1,500 litres per day with over twenty employees.

Many of the producers are traditional dairy farmers and others have previously sold regular yogurt. But, the sachet concept has allowed them to generate better returns for their social businesses. To facilitate easy access to the starter cultures, fifteen regional sachets distribution centres have been established in the three countries.

The process of establishing effective PUs begins by identifying people within communities who have access to milk and have affinity with food processing. Individuals or groups are trained in all the elements of the yogurt value chain, including milk quality control, hygienic production, packaging, marketing and book keeping. A key characteristic of the program is that all local producers sell under their own brand, and as a consequence they feel, and are responsible for, the quality of their own products. Some issues have arisen, where farmers have diluted milk before selling it to PUs; but this is why the lactometer is used. Milk curdling can occur and is usually a sign that the procedure has not been followed properly. Some smaller PUs have tried to use fractions of the sachets, in their eyes to save money, but the product quality has been poor in taste and texture. Rarely, when spoilage occurs, it is obvious to sight and taste, and these batches are destroyed. There has never been a case where the reason for problems with the fermented product has not been identified and corrected, which is testament to the process and diligence of the producers and trainers. One of the most urgent points for setting up a sustainable business with perishable food raw materials is the assurance of hygiene and good manufacturing practices. Hereto, the Yoba for Life foundation collaborates closely with the Dairy Development Authority with the aim to make sure that all local producers can comply with hygiene standards for food production.

All training materials are accessible free of charge (Yobafor-Life, 2017). In order to differentiate the probiotic yogurt from regular yogurts, the packaging carries a Yoba inside stamp to indicate the source of the cultures are the sachets (Figure 1). This is done to add value to the products since competitors will not be using such a well-documented probiotic, if they use any at all. Figure 2 illustrates active brand names of locally produced probiotic yogurts carrying the Yoba Inside label in Uganda. The weekly production volumes vary between 10 and 1,500 litres per day.

This program is an excellent example of translational microbiology that is designed to improve health and create wealth in form of economic activities and employment. The products improve health through delivery of a fermented food containing an effective probiotic strain. The acidified food inhibits pathogens that are in abundance in the local food and water (Drago et al., 1997; Kotloff et al., 2013) and the probiotic delivers prophylactic benefits through the production of by-products, such as short chain fatty acids, immune modulators and potentially neurochemicals (Kim et al., 2016; LeBlanc et al., 2017; Lyte, 2011; Rutten et al., 2011). An additional benefit of fermentation with a probiotic, is that all extracellular produced metabolites remain in the product, which is not the case when probiotics are added as functional ingredients. 


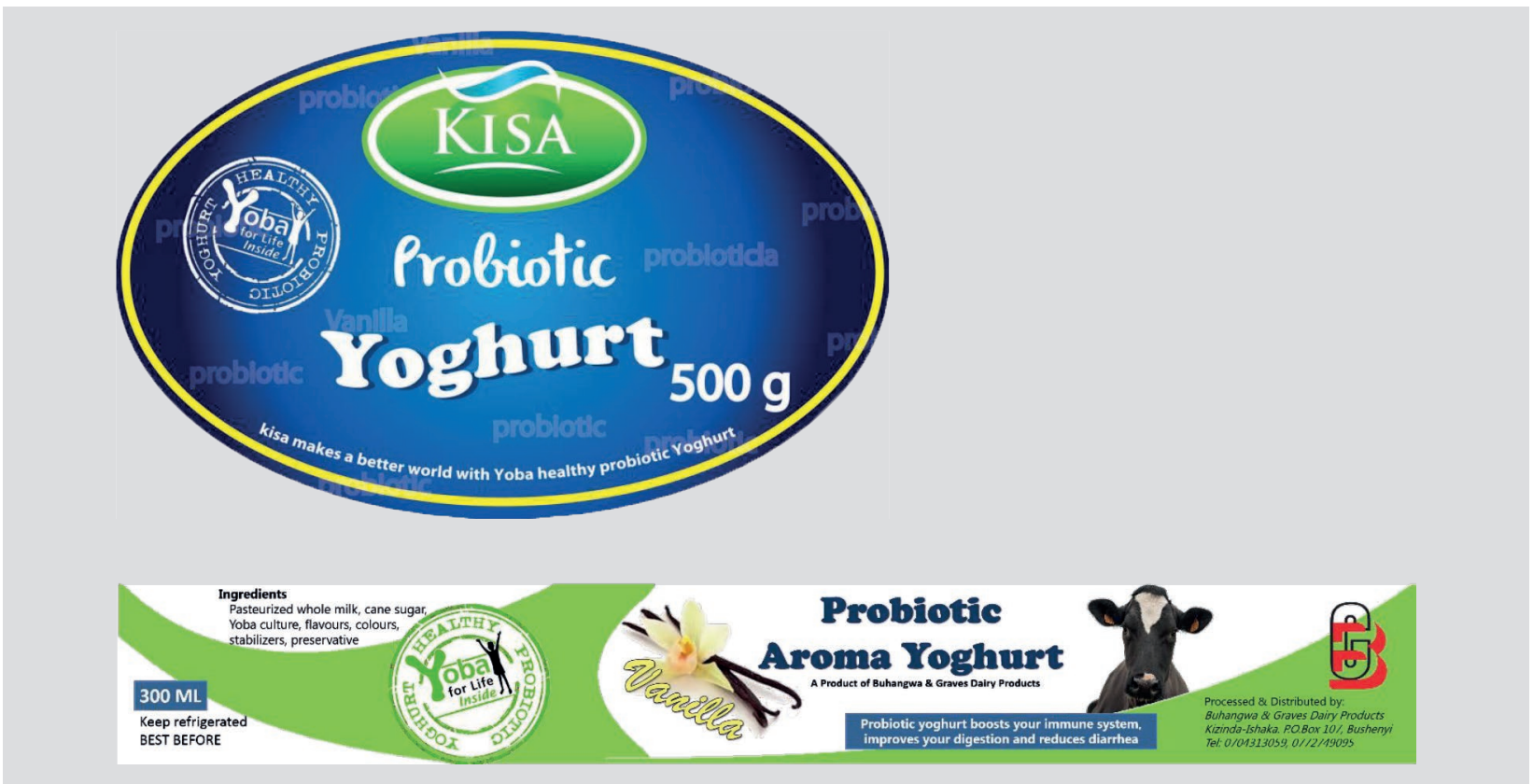

Figure 1. Example packaging labels of local probiotic yoghurt producer in Uganda carrying the Yoba inside stamp as brand added benefit. This represents the breakthrough production of the sachet by Yoba-for-Life.

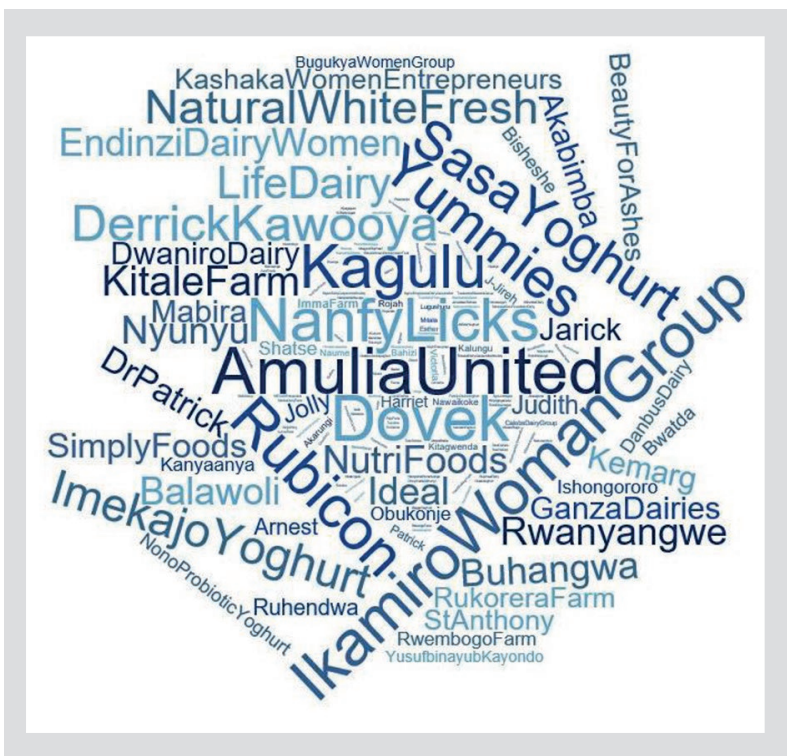

Figure 2. A word cloud listing the names of production units making probiotic yogurt in Uganda, with font size reflecting daily volumes.

\section{Learnings from Bangladesh}

The third model that was discussed focused on the growing population in Africa that is above the poverty line but is not affluent. Danone Communities is a mutual fund created ten years ago, with company employees contributing to fight malnutrition by empowering innovative social entrepreneurs to achieve sustainable social impact (Danone Communities, 2016; Yasmin, 2016). Danone Communities invests in social businesses as minority shareholders, providing capital in addition to technical and managerial expertise, with a view to eventually making a return on the investment.

The program started in Bangladesh in 2007, to alleviate malnutrition and develop a new business model generating income for local communities. A fermented dairy product, without a probiotic, was fortified with iron, iodine, vitamin A and zinc to cover $30 \%$ of a child's daily requirement was developed and sold at a price affordable to poor people, by the newly created Grameen Danone Foods Ltd. The milk is collected from small, independent local farmers, thereby contributing to their income. The distribution model of the fortified product was by door-to-door in rural areas, using women micro-entrepreneurs, as well as via small retail shops, enabling social impact throughout the value chain. However, expansion to cities, including Dhaka, was necessary to accomplish social and financial sustainability of the production factory, according to one analysis which viewed the initiative as a charity rather than a social business (Yasmin, 2016). This author noted that target consumers lacked knowledge about the product's benefits, and insufficient time was spent understanding their purchasing power, taste and preferences.

Nevertheless, the company claims to have reached three hundred thousand children in Bangladesh with the fortified yogurt providing a health benefit, as demonstrated by improved haemoglobin levels and linear growth (Sazawal et al., 2013). 
In northern Senegal, Danone Communities supports a network that collects fresh milk twice a day from 600 Fulani herders (Danone Communities, 2016). The fermentation process does not contain a probiotic but does prevent milk spoilage. The social enterprise distributes a range of affordable yogurts and Thiakry (sweet millet couscous dish, inspired from local eating habits). The next challenge will be to fortify the products with vitamins and minerals while keeping them affordable. In addition to Senegal, this model is being replicated in Kenya, Madagascar, India, China and Cambodia, with the intent of reaching one million beneficiaries. In Kenya, Danone invested in Brookside Dairies with a view to providing a further means to target middle-income consumers. Although not supplementing their products with probiotic strains, 400 local milk producers are enabling an estimated 70,000 malnourished children to receive yogurt enriched with essential micronutrients. In short, this third example is led by a multinational company and targeting the lowmiddle class.

\section{Future directions}

The three initiatives described all started by creating a strong basis at the supply side. In order to allow further expansion, stimulation of the demand side will be key. Information dissemination through scientific channels and social media is projected to provide consumers and healthcare providers with rapid access to clinical results, and identify the nearest location of sites making new and affordable probiotic food and supplements. This rapid translation of science to individual well-being will not only expand the beneficiaries of probiotics, but also fuel new social enterprises and economic business models. With widespread use of cell phones amongst all social classes, a texting app is currently being tested in rural Uganda to find out more about consumer responses to probiotics, and gauge whether availability of these fermented foods changes eating patterns. This methodology developed by the Dutch company 'Text to Change' has been proven useful in a number of studies to collect data from the field, on the demand as well the production site (De Lepper et al., 2013; Mangone et al., 2016).

The Argentinian model shows that economically poor countries can support distribution of these healthpromoting foods. Yet, even there fermented foods are not in the national Food Guide, nor are they in any other country surprisingly since their consumption could perhaps reduce the risk of lifestyle diseases (Chilton et al., 2015; Sybesma et al., 2017).

The three initiatives discussed herein all focus on milk. Although milk production is expected to increase substantially on the African continent (World milk production growth, 2015), which augers well for this program, it is not the most sustainable protein source in the daily diet, and during the dry season in Africa, milk production decreases. For this reason, and to expand the reach of the sachets to milk-poor countries, experiments were performed to show that the strains in the Yoba/Fiti sachets can also ferment millet, soy and corn (Di Stefano et al., 2017). Pearl millet, in particular, has a long history of use in Africa, and its drought resistance makes it a good crop to deliver the benefits of the probiotics. Its production decreased with the introduction of maize, which does not require the hulling and processing needed for millet. In addition, the yield from the nutrient-rich millet is not as high as other cereals (barely $600 \mathrm{~kg}$ per hectare) like maize, and it has been described as a 'lost' crop (Lost Crops, 1996). However, the sometimes-deadly aflatoxins released by Aspergillus sp. on contaminated maize (Kouadio et al., 2014), and the continued exposure of children to these toxins (Nduti et al., 2016) has led to proposals to return to consumption of fermented millet, in which the probiotic Yoba 2012 and GR-1 strains degrade the aflatoxins (Ahlberg et al., 2015; Mokoena et al., 2006; Musika et al. unpublished; Nduti et al., 2017; Verheecke et al., 2016). For maize and other cereals, the use of microorganisms to detoxify aflatoxins has been researched, and by means of the locally made probiotic fermented food, this is expected to contribute to the reduction of a significant disease risk factor (Sybesma et al., 2015).

The opportunity exists to identify microbes that can deliver specific benefits to inhabitants of tropical regions. For example, Lindsay et al. (2015) conducted a study with microbiota of the stools of 1,300 children with moderateto-severe diarrhoea and 1,735 without diarrhoea in Kenya, and reported a correlation between presence of some Lactobacillus species and protective additive effects against diarrhoea when infected with Shigella. In a follow-up study, it appeared that the supernatant of an Lactobacillus salivarius isolated from the stool of a Kenyan child inhibited growth of Shigella boydii, Shigella sonnei, Shigella dysenteriae and enterotoxigenic Escherichia coli (ETEC) in vitro (Stine O.C., personal communication). Future research will focus on the potential to make fermented food with this strain, and to verify its curative and/or preventive effect against Shigella induced diarrhoea.

\section{Concluding remarks}

We evaluated three different models of sustainable concepts designed to use local production and sales of probiotic fermented foods. All models include scalable, sustainable, knowledge intensive, and locally grounded innovations. Two of the options create value and operate in line with the principles of creating fortune at the bottom of the pyramid (Prahalad and Hart, 2002). The third non-probiotic model aims to bring highly nutritious and affordable foods to consumers emerging from poverty. 
The FFFL program and Danone do not provide any funds per se to local communities and producers, and budgets are only allocated to pay staff who facilitate trainings and coordination. Although the Yogurito concept is completely sponsored by the Argentina government, we reason that the expected return on investment in serving 300,000 children daily with probiotic yoghurt will be positive because of reduced illnesses, fewer visits to doctors and higher school attendance. In addition to the generation of income for local producers and improvement in health of the populations consuming the probiotic supplemented fermented foods, the FFFL program touches all parts of the value chain as shown in Figure 3. Further generation of evidence substantiating societal and health benefits, and engagement of communities and government agencies will certainly strengthen the programs.

The initiatives described in this article show that there is a role for researchers aligned with governments (Yogurito), the private sector (Danone Communities), and civil society (WHE/Y4L) in helping the most challenged people on our planet who are faced with poverty, malnutrition, infectious diseases and acts of violence. Each element has its own strengths and weaknesses, opportunities and threats, as summarised in Table 1. By emphasising sustainability through empowering people to use local resources to combat malnutrition and poverty, many of the United Nations' seventeen Sustainable Development Goals (SDGs) to end poverty, protect the planet, and ensure prosperity for all can be met (United Nations, 2014). The simple guidelines for success are to make it easy, understood, desirable, rewarding, and a habit.
As a take home message, three different initiatives are described in this paper that show the application of probiotics to poor people in developing countries who currently would not otherwise have access to their healthpromoting benefits. In the case of the East Africa example, the initiative also provides empowerment to women and dairy farmers, and socio-economic benefits to the producers.

\section{Acknowledgements}

The support of the International Scientific Association for Probiotics and Prebiotics and CIFSRF/IDRC Canada are appreciated. The discussion group also included Serge Carrier, Nikhat Contractor, Eden Ephraim Gebreselassie, Annahita Ghessemi, Anu Kaukovirta-Norja, Tami Mackle, and Jonas Faijerson Saljo.

\section{Conflicts of interest}

GR, RK and WS are all involved in the FFFL program in East Africa, but receive no financial benefits from doing so. SA is employed by an institute that created the probiotic used in Argentina, but she has no financial stake in its sales and success. RB-S is employed by Danone, a manufacturer of probiotics, but the review does not promote any Danone commercial product, and RB-S would not personally benefit if this inadvertently occurred. MC and JETvHV are employed by a distributor of probiotics, and neither benefit personally from the social enterprise activities discussed herein. HV is a physician scientist and DMS

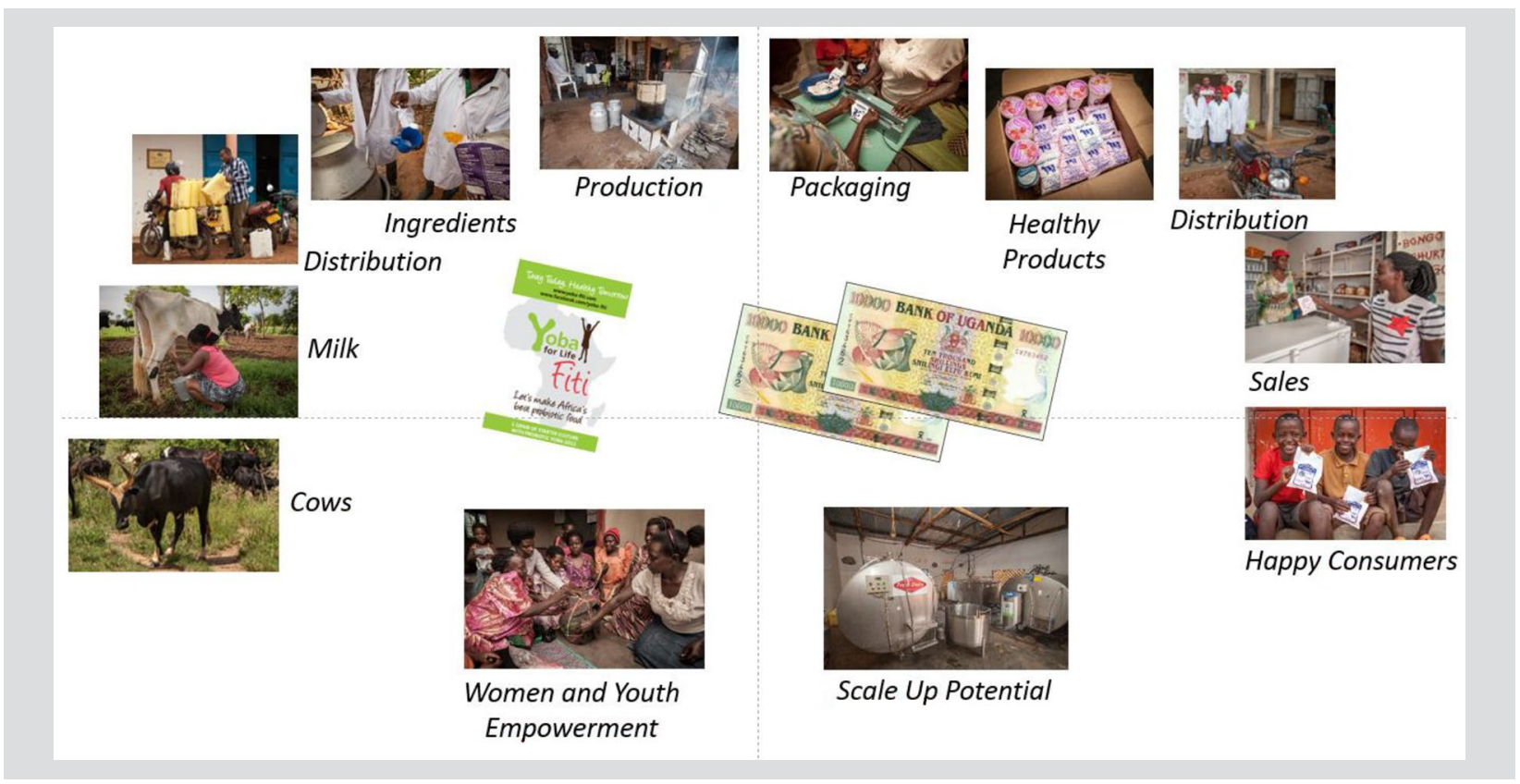

Figure 3. Probiotic yoghurt impacts all stages of the value chain at the bottom of the pyramid through affordable probiotic starter cultures. 
Table 1. SWOT (Strength, Weakness, Opportunity, Threat) analysis of three bottom of pyramid initiatives to improve health and wealth by means of locally produced probiotic fermented food.

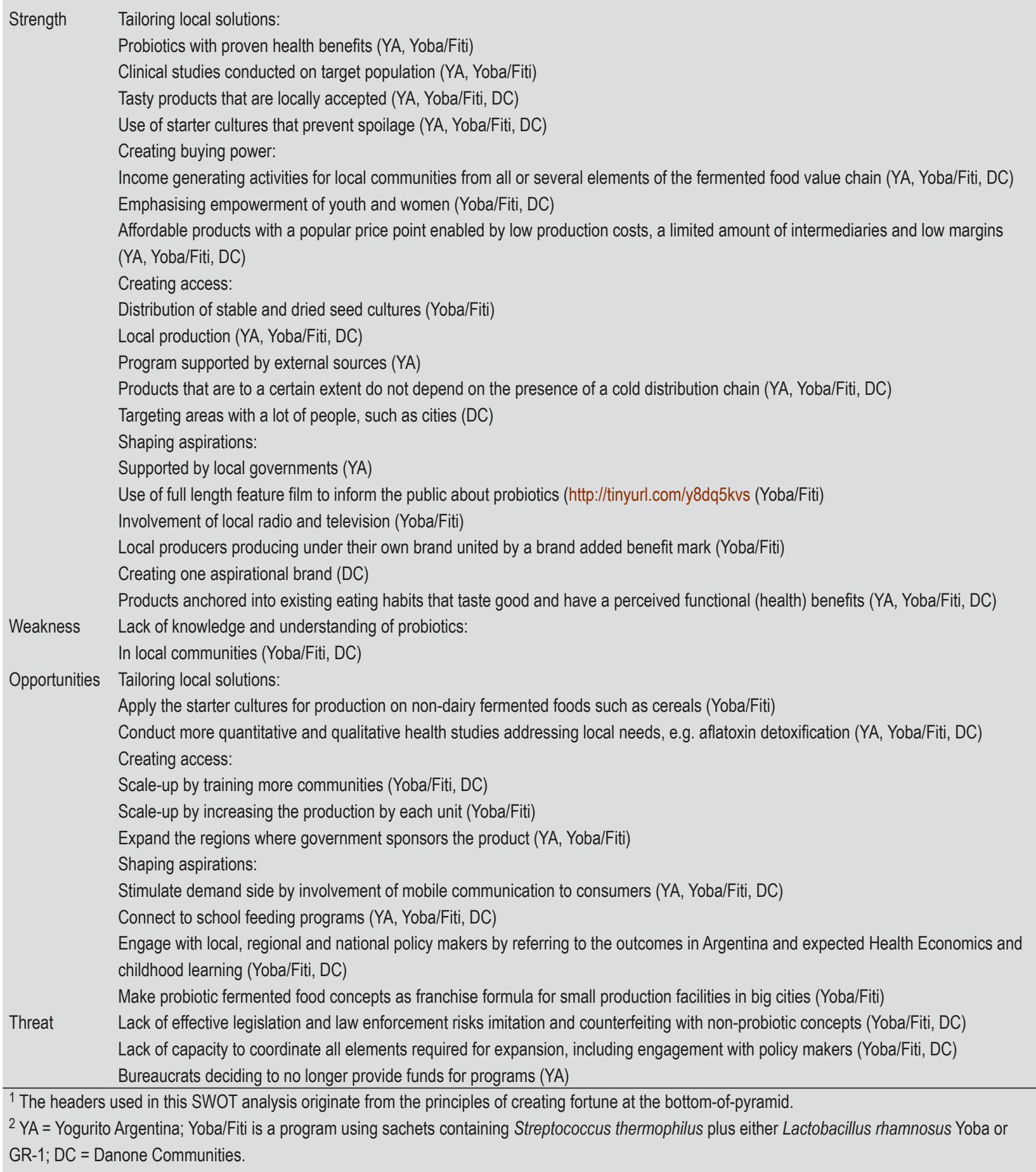


is a scientist with no personal affiliation with any of the probiotics discussed.

\section{References}

Ahlberg, S.H., Joutsjoki, V. and Korhonen, H.J., 2015. Potential of lactic acid bacteria in aflatoxin risk mitigation. International Journal of Food Microbiology 207: 87-102.

Allen, L., Cobiac, L. and Townsend, N., 2017. Quantifying the global distribution of premature mortality from non-communicable diseases. Journal of Public Health 39(4): 698-703.

Anukam, K.C., Osazuwa, E.O., Osadolor, B.E., Bruce, A.W. and Reid, G., 2008. Yogurt containing probiotic Lactobacillus rhamnosus GR-1 and L. reuteri RC-14 helps resolve moderate diarrhea and increases CD4 count in HIV/AIDS patients. Journal of Clinical Gastroenterology 42(3): 239-243.

Chilton, S.N., Burton, J.P. and Reid, G., 2015. Inclusion of fermented foods in food guides around the world. Nutrients 7(1): 390-404.

Countryeconomy.com, 2017. Argentina. Available at: https:// countryeconomy.com/gdp/argentina.

Danone Communities, 2016. Danone.communities: 'Increasing our impact, together!' Available at: http://tinyurl.com/yczkkca7.

De Lepper, A.M., Eijkemans, M.J., Van Beijma, H., Loggers, J.W., Tuijn, C.J. and Oskam, L., 2013. Response patterns to interactive SMS health education quizzes at two sites in Uganda: a cohort study. Tropical Medicine International Health 18: 516-521.

Di Stefano, E., White, J., Seney, S., Hekmat, S., McDowell, T., Sumarah, M. and Reid, G., 2017. A novel millet-based probiotic fermented food for the developing world. Nutrients 9: E529.

Drago, L., Gismondo, M.R., Lombardi, A., De Haën, C. and Gozzini, L., 1997. Inhibition of in vitro growth of enteropathogens by new Lactobacillus isolates of human intestinal origin. FEMS Microbiology Letters 153: 455-463.

Franz, C.M., Huch, M., Mathara, J.M., Abriouel, H., Benomar, N., Reid, G., Galvez, A. and Holzapfel, W.H., 2014. African fermented foods and probiotics. International Journal of Food Microbiology 190: 84-96.

Hemme, T., 2015. Current status of milk production worldwide and expected development to 2025. Available at: https://tinyurl.com/ y92knj3n.

Hill, C., Guarner, F., Reid, G., Gibson, G.R., Merenstein, D.J., Pot, B., Morelli, L., Canani, R.B., Flint, H.J., Salminen, S., Calder, P.C. and Sanders, M.E., 2014. Expert consensus document. The International Scientific Association for Probiotics and Prebiotics consensus statement on the scope and appropriate use of the term probiotic. Nature Reviews in Gastroenterology and Hepatology 11: 506-514.

Horton, R. and Lo, S., 2015. Planetary health: a new science for exceptional action. Lancet 386(10007): 1921-1922.

Irvine, S.L., Hummelen, R., Hekmat, S., Looman, C.W., Habbema, J.D. and Reid, G., 2010. Probiotic yogurt consumption is associated with an increase of CD4 count among people living with HIV/AIDS. Journal of Clinical Gastroenterology 44: e201-205.

Keszei, A.P., Schouten, L.J., Goldbohm, R.A. and Van den Brandt, P.A., 2010. Dairy intake and the risk of bladder cancer in the Netherlands Cohort Study on Diet and Cancer. American Journal of Epidemiology 171: 436-446.
Kim, S.H., Jeung, W., Choi, I.D., Jeong, J.W., Lee, D.E., Huh, C.S., Kim, G.B., Hong, S.S., Shim, J.J., Lee, J.L., Sim, J.H. and Ahn, Y.T., 2016. Lactic acid bacteria improves Peyer's Patch cell-mediated immunoglobulin A and tight-junction expression in a destructed gut microbial environment. Journal of Microbiology and Biotechnology 26: $1035-1045$.

Kort, R. and Sybesma, W., 2012. Probiotics for everybody. Trends in Biotechnology 30: 613-615.

Kort, R., Westerik, N., Mariela Serrano, L., Douillard, F.P., Gottstein, W., Mukisa, I.M., Tuijn, C.J., Basten, L., Hafkamp, B., Meijer, W.C., Teusink, B., De Vos, W.M., Reid, G. and Sybesma, W., 2015. A novel consortium of Lactobacillus rhamnosus and Streptococcus thermophilus for increased access to functional fermented foods. Microbial Cell Factories 14: 195.

Kotloff, K.L., Nataro, J.P., Blackwelder, W.C., Nasrin, D., Farag, T.H., Panchalingam, S., Wu, Y., Sow, S.O., Sur, D., Breiman, R.F., Faruque, A.S., Zaidi, A.K., Saha, D., Alonso, P.L., Tamboura, B., Sanogo, D., Onwuchekwa, U., Manna, B., Ramamurthy, T., Kanungo, S., Ochieng, J.B., Omore, R., Oundo, J.O., Hossain, A., Das, S.K., Ahmed, S., Qureshi, S., Quadri, F., Adegbola, R.A., Antonio, M., Hossain, M.J., Akinsola, A., Mandomando, I., Nhampossa, T., Acácio, S., Biswas, K., O’Reilly, C.E., Mintz, E.D., Berkeley, L.Y., Muhsen, K., Sommerfelt, H., Robins-Browne, R.M. and Levine, M.M., 2013. Burden and aetiology of diarrhoeal disease in infants and young children in developing countries (the Global Enteric Multicenter Study, GEMS): a prospective, case-control study. The Lancet 382: 209-222.

Kouadio, J.H., Lattanzio, V.M., Ouattara, D., Kouakou, B. and Visconti, A., 2014. Assessment of mycotoxin exposure in Côte d'ivoire (Ivory Coast) through multi-biomarker analysis and possible correlation with food consumption patterns. Toxicology International 21: 248-257.

LeBlanc, J.G., Chain, F., Martín, R., Bermúdez-Humarán, L.G., Courau, S. and Langella, P., 2017. Beneficial effects on host energy metabolism of short-chain fatty acids and vitamins produced by commensal and probiotic bacteria. Microbial Cell Factories 16: 79.

Lindsay, B., Saha, D., Sanogo, D., Das, S.K., Omore, R., Farag, T.H., Nasrin, D., Li, S., Panchalingam, S., Levine, M.M., Kotloff, K., Nataro, J.P., Magder, L., Hungerford, L., Faruque, A.S., Oundo, J., Hossain, M.A., Adeyemi, M. and Stine, O.C., 2015. Association between Shigella infection and diarrhea varies based on location and age of children. American Journal of Tropical Medicine and Hygiene 93: 918-924.

Lost crops of Africa, 1996. Board on science and technology for international development national research council. National Academy Press, Washington, DC, USA, pp. 77-92. Available at: https://tinyurl.com/ya8vexkg.

Lyte, M., 2011. Probiotics function mechanistically as delivery vehicles for neuroactive compounds: microbial endocrinology in the design and use of probiotics. Bioessays 33: 574-581.

Mangone, E.R., Agarwal, S., L'Engle, K., Lasway, C., Zan, T., Van Beijma, H., Orkis, J. and Karam, R., 2016. Sustainable cost models for mhealth at scale: modeling program data from m4RH Tanzania. PLoS ONE 11: e0148011. 
Marco, M.L., Heeney, D., Binda, S., Cifelli, C.J., Cotter, P.D., Foligné, B., Gänzle, M., Kort, R., Pasin, G., Pihlanto, A., Smid, E.J. and Hutkins, R., 2017. Health benefits of fermented foods: microbiota and beyond. Current Opinions in Biotechnology 44: 94-102.

Mokoena, M., Chelule, P. and Gqaleni, N., 2006. The toxicity and decreased concentration of aflatoxin B1 in natural lactic acid fermented maize meal. Journal of Applied Microbiology 100: 773-777.

Nduti, N.N., McMillan, A., Seney, S., Sumarah, M., Njeru, P., Mwaniki, M. and Reid, G., 2016. Investigating probiotic yoghurt to reduce aflatoxin B1 among school children in eastern Kenya: preliminary study. International Dairy Journal 63: 124-129.

Nduti, N.N., Njeru, P., Mwaniki, M. and Reid, G., 2017. Aflatoxin variations in maize flour and grains collected from various regions of Kenya. African Food and Agriculture Nutrition and Development 17: $11743-11756$

Omenn, G.S., 2010. Evolution in health and medicine Sackler colloquium: evolution and public health. Proceedings of the National Academy of Sciences of the USA 107, Suppl. 1: 1702-1709.

Podolsky, S., 1998. Cultural divergence: Elie Metchnikoff's Bacillus bulgaricus therapy and his underlying concept of health. Bulletins of the History of Medicine 72: 1-27.

Postler, T.S. and Ghosh, S., 2017. Understanding the holobiont: how microbial metabolites affect human health and shape the immune system. Cell Metabolism 26: 110-130.

Prahalad, C.K. and Hart, S.L., 2002. The fortune at the bottom of the pyramid. Strategy and Business 26: 5-16.

Reid, G., 2010. The potential role for probiotic yogurt for people living with HIV/AIDS. Gut Microbes 1: 411-414.

Rutten, N.B., Besseling-Van der Vaart, I., Klein, M., De Roock, S., Vlieger, A.M. and Rijkers, G.T., 2011. In vitro assessment of the immunomodulatory effects of multispecies probiotic formulations for management of allergic diseases. Beneficial Microbes 2: 183-192.

Salva, S., Villena, J. and Alvarez, S. 2010. Immunomodulatory activity of Lactobacillus rhamnosus strains isolated from goat milk: impact on intestinal and respiratory infections. International Journal of Food Microbiology 141: 82-89.

Sazawal, S., Habib, A.K.M., A., Dhingra, U., Dutta, A., Dhingra, P., Sarkar, A., Deb, S., Alam, J., Husna, A. and Black, R.E., 2013. Impact of micronutrient fortification of yoghurt on micronutrient status markers and growth - a randomized double blind controlled trial among school children in Bangladesh. BMC Public Health 13: 514.
Sonestedt, E., Wirfält, E., Wallström, P., Gullberg, B., Orho-Melander, M. and Hedblad, B., 2011. Dairy products and its association with incidence of cardiovascular disease: the Malmö diet and cancer cohort. European Journal of Epidemiology 26: 609-618.

Sybesma, W., Blank, I. and Lee, Y.K., 2017. Sustainable food processing inspired by nature. Trends in Biotechnology 35: 279-281.

Sybesma, W., Kort, R. and Lee, Y-K., 2015. Locally sourced probiotics, the next opportunity for developing countries. Trends in Biotechnology 33: 197-200.

United Nations, 2015. Sustainable development goals. Available at: https://tinyurl.com/zlecl5g.

Verheecke, C., Liboz, T. and Mathieu, F., 2016. Microbial degradation of aflatoxin b1: current status and future advances. International Journal of Food Microbiology 237: 1-9.

Villena, J., Salva, S., Núñez, M., Corzo, J., Tolaba, R., Faedda, J., Font, G. and Alvarez, S., 2012. Probiotics for everyone! The novel immunobiotic Lactobacillus rhamnosus CRL1505 and the beginning of social probiotic programs in Argentina. International Journal of Biotechnology for Wellness Industries 1: 189-198.

Westerik, N., Wacoo, A.P., Sybesma, W. and Kort, R., 2016. Novel production protocol for small-scale manufacture of probiotic fermented foods. Journal of Visualized Experiments 10: 115.

World Atlas, 2017. Most malnourished countries in the world. Available at: https://tinyurl.com/yc44ogat.

World Statistics, 2014. Life expectancy for countries. Available at: https://tinyurl.com/p3tjd3s.

Yasmin, N.N., 2016. Sustainability of a social business: a case study on Grameen Danone Foods Limited. Asian Business Consortium 6: 167-174.

Yoba for life, 2017. Producers. Available at: http://www.yoba4life. org/producers.

Younes, J.A., Lievens, E., Hummelen, R., Van der Westen, R., Reid, G. and Petrova, M.I., 2017. Women and their microbes: the unexpected friendship. Trends in Microbiology 26: 16-32.

Zelaya, H., Tsukida, K., Chiba, E., Marranzino, G., Alvarez, S., Kitazawa, H., Agüero, G. and Villena, J., 2014. Immunobiotic lactobacilli reduce viral-associated pulmonary damage through the modulation of inflammation-coagulation interactions. International Immunopharmacology 19: 161-173. 
